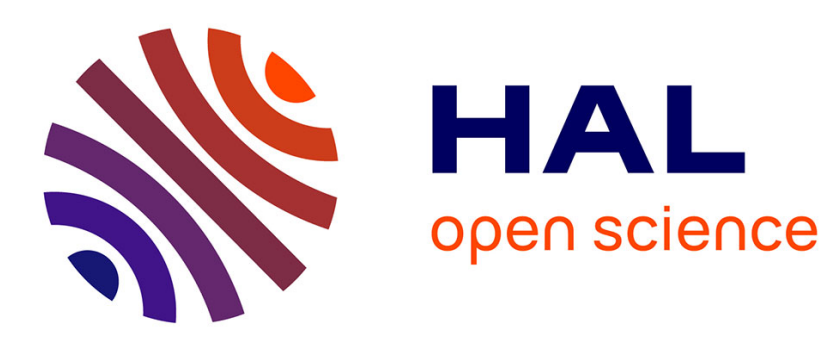

\title{
Localization due to Damage in Two-Direction Fiber-Reinforced Composites
}

François Hild, P.-L. Larsson, F.A. Leckie

\section{To cite this version:}

François Hild, P.-L. Larsson, F.A. Leckie. Localization due to Damage in Two-Direction FiberReinforced Composites. Journal of Applied Mechanics, 1996, 63 (2), 10.1115/1.2788867 . hal01636234

\section{HAL Id: hal-01636234 \\ https://hal.science/hal-01636234}

Submitted on 31 Oct 2019

HAL is a multi-disciplinary open access archive for the deposit and dissemination of scientific research documents, whether they are published or not. The documents may come from teaching and research institutions in France or abroad, or from public or private research centers.
L'archive ouverte pluridisciplinaire HAL, est destinée au dépôt et à la diffusion de documents scientifiques de niveau recherche, publiés ou non, émanant des établissements d'enseignement et de recherche français ou étrangers, des laboratoires publics ou privés. 


\section{F. Hild' \\ Department of Mechanical and \\ Environmenta| Engineering, \\ Universily of Californla, \\ Santa Barbara, CA $93106-5070$ \\ P.-L. Larsson \\ Depariment of Solid Mechanics, \\ Localization due to Damage in Two-Direction Fiber-Reinforced Composites}

Royal Institule of Tochnology,

S-100 44 Stockholm, Swoden

\section{F. A. Leckie}

Department of Mechanical and

Environmental Engineering,

Unlversily of Caiflornia.

Santa Barbara, CA $93106-5070$

Fiber pult-out is one of the fracture features of fiber-reinforced ceramic matrix composites. The onset of this mechanism is predicted by using continum damage mechanics, and corresponds to a localization of deformation. After deriving two damage models from a uniaxial bundle approach, different configurations are analyzed through numerical methods. For one model some very simple criteria can be derived, whereas for the second one none of these criteria can be derived and the general criterion of localization must be used.

\section{Introduction}

Ceramic matrix composites (CMCs) can either be reinforced by libers in one direction or by fibers in two directions. The aim of this paper is to study composites reinforced with fibers in two perpendicular directions by extending a previous study on CMCs with fibers in one direction (Hild el al., 1992).

The rupture of most of the CMCs involves two separate failure mechanisms. The first mechanism is matrix cracking. The matrix cracks develop and their density saturates as the load level increases. The second mechanism is fiber breakage accompanied by fiber pull-out. Eventually, the final tupture will take place around one of the matrix cracks: it corresponds to localized fiber pull-out due to fiber breakage. The occurrence of this mechanism corresponds to the appearance of a macrocrack and will be described by a localization of seformation. The initiation of macrocracks in a structure during scrvice often constitutes the early stage of the final failure of the structure. Starting from a material that is assumed free from any initjal (tefect, the initiation' of macrocracks can be predicted using continuum damage mechanics. The driving force is fiber breakage, which is accompanied by distributed pull-out. The approach using localization has successfully been used for ductile materials (Billardon and Doghti, 1989a, b; Doghri, 1989). The initiation stage is considered as the onset of a surface across which the velocity gradient is discontinuous. Under small deformation assumptions, this phenomenon is mainly driven by the damage mechanism that causes strain softening. For CMCs, the damage mechanism is related to fiber breakage, and the damage variable describes the percentage of broken fibers (Hild et al," 1992).

Although localization can be studied at the scale of fibers bonded to a matrix through an interface (Benallal et al, 1991a), i.e., at a micro level, localization also can be analyzed at a mesolevel, when the material is assumed to be homogeneous. Continuum danage mechanics, which represents a local ap-

' Visiling Postgruduare Rescarcher, also at the I,aboratoire de Mćcanique at Technologie, E.N.S. de Cachan/C.N.K.S./Universite Paris G, 61 avenue du P'résident Wilson, F-94235 Cácluan Cedex Itrunce. proach to fracture (Benallal et al., 1991b), constitutes an effin cient tool for this purpose. The progressive deteriotation of the material is modeled by internal variables defined at the meso level. These variables are called damage variables. The damage state and the evolution of these variables is obtained through a uniaxial study based on fiber breakage (Coleman, 1958; Curtin, 1991). A two-dimensional plane-stress analysis is performed based on an extended model. The loss of uniqueness and the localization are studied for shear free states. A criterion referring to a critical value of the damage or to a maximum normal stress can describe the localization, which constituscs an objective critction, from a design point of view.

\section{Localization and Loss of Uniqueness}

The failure at a meso level, with the initiation of a macrocrack, is defined as the bifurcation of the rate problem in certain modes, viz. the appearance of a surface across which the velocity gradient is discontinuous (Billardon and Doghri, 1989a). This phenomenon is referred to as localization, and corresponds to the failure of the ellipticity condition. The condition of localization can also be compared to the loss of uniqueness of the rate problem.

Stationary waves were studied by Hadamatel (1903) in elasticily and by Hill (1962) and Mandel (1962) in elastoplasticity. Rice (1976) related the localization of plastic shear bands to jumps of the velocity gradient. Borté and Maier (1989) have given necessary and sufficient conditions for the onset of modes inside the body, and extended the results given by Rice (1976) and Rice and Rudnicki (1975, 1980).

Under small strain assumption and in elasticity coupled with damage, the behavior of a material is assumed to be described by the following piece-wise linear rate constitutive law:

$$
\dot{\delta}=\left\{\begin{array}{lll}
\mathbf{E}: \boldsymbol{\epsilon} & \text { if } & D=0 \\
\mathbf{H}: \boldsymbol{\epsilon} & \text { if } & D \neq 0
\end{array}\right.
$$

where $\dot{\sigma}$ and $\varepsilon$, respectively, denote the stress and strain rates, $\mathbf{E}$ and $\mathbf{H}$ are fourth rank tensors, $\mathbf{E}$ is assumed to be positive definite, and $D$ is either a single damage variable or a set of damage variables.

Localization occurs inside the body, if and only if (Rudnicki and Rice, 1975; Borré and Maier, 1989; Benallal et al., 1991a)

$\operatorname{Det}(\boldsymbol{n} \cdot \mathbf{H} \cdot \boldsymbol{n})=0$ for a vector $n \neq 0$ and at a point inside a structure $\Omega$. 
This criterion corresponds to the failure of the ellipticity condition of the rate equilibrium equation; it also can be used as an indicator of the local failure of the material, at a meso scale (Billardon and Doghri, 1989a).

Furthermore, any loss of uniqueness, considered as bifurcation of the rate boundary value problem, is excluded provided

$$
\boldsymbol{\sigma}: \mathbf{k}>0 \text {. }
$$

In this study, the quantity that defines loss of uniqueness and localization is the linear tangent modulus $\mathbf{H}$. In the following, we analyze loss of uniqueness and loss of ellipticity (i.e., localization) for states when

$$
\left\{\begin{array}{l}
\epsilon_{11}=\alpha \epsilon_{22} \\
\epsilon_{12}=0
\end{array}\right.
$$

The parameter $\alpha$ is referred to as the strain ratio and its inverse is denoted by $\beta$. These particular states only are considered. When the hypothesis of Eq. (4) is satisfied, the nonvanishing components of the vector $n$ are $n_{1}$ and $n_{2}$, and the matrix $\mathbf{A}=$ $\boldsymbol{n} \cdot \mathbf{H} \cdot \boldsymbol{n}$ reduces to (Ortiz et al., 1987)

$$
\mathbf{A}=\left[\begin{array}{cc}
n_{1}^{2} H_{1111}+n_{2}^{2} H_{1212} & n_{1} n_{2}\left(H_{1212}+H_{1122}\right) \\
n_{1} n_{2}\left(H_{1212}+H_{2211}\right) & n_{1}^{2} H_{1212}+n_{2}^{2} H_{2222}
\end{array}\right] .
$$

If we rewrite $\left(n_{1}, n_{2}\right)=(\cos \theta, \sin \theta), X=\tan ^{2} \theta$, then the localization condition is equivalent to finding real positive roots of the following equation:

$$
a X^{2}+b X+c=0
$$

with

$$
\begin{gathered}
a=H_{1212} H_{2222} \\
b=H_{1111} H_{2222}-H_{1122} H_{2211}-H_{1122} H_{1212}-H_{2211} H_{1212} \\
c=H_{1212} H_{1111} .
\end{gathered}
$$

If real positive roots are found, then the localization direction is perpendicular to the vector $\left(n_{1}, n_{2}, 0\right)=(\cos \theta, \sin \theta, 0)$, characterized by the angle $\theta$ (Fig. I). The values of $H_{1111}, H_{2222}$, $H_{1 \mid 22}, H_{2211}$ and $H_{1212}$ are model dependent and specific models are now developed.

\section{Constitutive Laws}

This section is concerned with the development of two constitutive laws in the case of CMCs reinforced in two perpendicular directions. At constant temperature, the behavior of a CMC reinforced by unidirectional fibers in the $x_{2}$-direction (see Fig. 1) can be characterized by the Helmholtz free energy density $\psi_{2}$, which is a function of the state variables $\epsilon_{11}, \epsilon_{22}, \epsilon_{12}$, and the damage variable $D_{2}$ in the $x_{2}$-direction

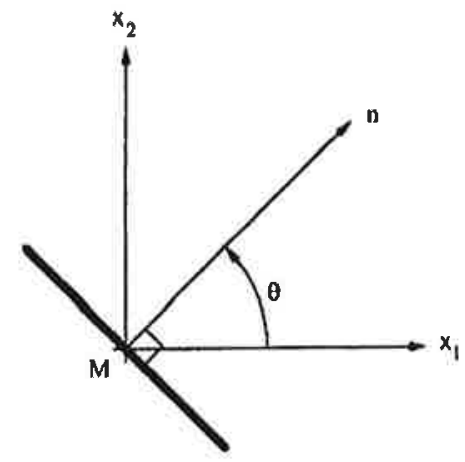

Fig. 1 Looalization modo

$$
\rho \psi_{2}=\rho \psi\left(\epsilon_{11}, \epsilon_{22}, \epsilon_{12}, D_{2}, f_{2}, k_{2}\right),
$$

where $D_{2}$ represents the fiber degradation in the $x_{2}$-direction, $E_{2}$ the Young's modulus in the $x_{2}$-direction, $\nu_{12}$ the Poisson's ratio, $k_{2}$ the ratio of the Young's modulus in the fiber direction $\left(E_{2}\right)$ to the Young's modulus in the transverse direction $\left(E_{1}\right)$, and $G_{12}$ the shear modulus. It is worth noting that the elastic quantities depend on the volume fraction of fibers. The expression for the general Helmholtz free energy density $\psi$ is given by

$\rho \psi(x, y, z, d, f, k)$

$$
=\frac{E_{2}(f)}{2}\left[\frac{x^{2}+2 \nu_{12} k(1-d) x y+k y^{2}}{k\left\{1-\nu_{12}^{2} k(1-d)\right\}}\right]+2 G_{12} z^{2}
$$

where $\rho$ is the material density, $x, y, z$ are dummy variables representing strains, $d$ damage, $f$ volume fraction, and $k$ Young's moduli ratio. The stresses and the thermodynamic force $Y_{2}$ associated to the damage variable $D_{2}$ are derived from the Helmholtz free energy density $\psi_{2}$ as follows:

$$
\begin{aligned}
\sigma_{11}=\rho \frac{\partial \psi_{2}}{\partial \epsilon_{11}} \quad \sigma_{22} & =\rho \frac{\partial \psi_{2}}{\partial \epsilon_{22}} \quad 2 \sigma_{12}=\rho \frac{\partial \psi_{2}}{\partial \epsilon_{12}} \\
Y_{2} & =\rho \frac{\partial \psi_{2}}{\partial D_{2}} .
\end{aligned}
$$

The explicit expressions for the stresses related to the strains and the damage variable modeling the fiber degradation in the $x_{2}$-direction are given by

$$
\begin{gathered}
\sigma_{11}=\frac{E_{2}}{k_{2}\left[1-\nu_{12}^{2}\left(1-D_{2}\right) k_{2}\right]}\left[\epsilon_{11}+\nu_{12}\left(1-D_{2}\right) k_{2} \epsilon_{22}\right] \\
\sigma_{22}=\frac{E_{2}\left(1-D_{2}\right)}{1-\nu_{12}^{2}\left(1-D_{2}\right) k_{2}}\left(\epsilon_{22}+\nu_{12} \epsilon_{11}\right) \\
\sigma_{12}=2 G_{12} \epsilon_{12}
\end{gathered}
$$

The damage state of fibers in the $x_{2}$-direction, $D_{2}$ can be related to the stress (and is denoted by $D_{2}^{(1)}$ ) or strain state (and is denoted by $D_{2}^{(2)}$ ). The relationship is either implicit in terms of the normal stress in the $x_{2}$-direction (model \#1)

$$
\begin{aligned}
& D_{2}^{(1)}=1-\exp \left[-\left\{\frac{\sigma_{22}}{\left(1-D_{2}^{(1)}\right) f_{2} \sigma_{c}}\right\}^{m+1}\right] \\
& \text { if } \epsilon_{22}>0 \text { and } \xi_{22}>0
\end{aligned}
$$

where $m$ is the shape parameter of a Weibull law (Weibull, 1939), $\sigma_{c}$ the characteristic strength (Henstenburg and Phoenix, 1989), and $f_{2}$ is the volume fraction of fibers in the $x_{2}$-direction; or explicit in terms of the normal strain in the $x_{2}$-direction (model \#2)

$$
\begin{aligned}
& D_{2}^{(2)}=1-\exp \left[-\left(\frac{\epsilon_{22}}{\epsilon_{t}}\right)^{m+1}\right] \\
& \text { if } \epsilon_{22}>0 \text { and } \epsilon_{22}>0
\end{aligned}
$$

where $\epsilon_{c}$ is related to the characteristic strength $\sigma_{c}$ by $\sigma_{t:}=E_{r} \epsilon_{c}$ ( $E_{F}$ is the Young's modulus of the fibers). Both models describe the same material behavior when subjected to uniaxial tension. However, the models give different predictions for multiaxial loading states (Hild et al.. 1992). It is worth noting that the damage evolution laws are a priori independent of the volume, since we assume that the local behavior of the fiber degradation is not dependent on the total length of the fiber (Curtin, 1991). This type of behavior is abserved when diseributed pull-out happens in conjunction with fiber breakage, and it can be shown that in most practical cases, the statistics driving the fiber breakage is independent of the total length of the composite. On the 
other hand, if the composite length becomes very small, a length dependence is found again (Hild et al., 1994), and in this case the evolution of the damage variable is mainly given by a fiberbundle-type of behavior, which leads to replacing $m+1$ by $m$, the characteristic strength $\sigma_{c}$ by $\sigma_{0}\left(L / L_{0}\right)^{-1 / m}$, where $\sigma_{0}$ is the scale parameter of a Weibull law, and the scale strain $\epsilon_{c}$ by $\epsilon_{0}\left(L / L_{0}\right)^{-1 / m 1}$, where $L_{0}$ is the gauge length at which the scale parameter has been identified, and $\sigma_{0}=E_{F} \epsilon_{i p}$. Since the results are the same for both damage evolution laws when the previous permutation is used, we will just express them in the case when the model is length independent, which is the most relevant in practice.

If the fibers are in the $x_{1}$-direction then the breakage can be modeled by a dainage variable denoted by $D_{1}$. Using Eq. (9), the Helmholtz free energy density $\rho \psi_{1}$ is given by

$$
\rho \psi_{1}=\rho \psi\left(\epsilon_{22}, \epsilon_{11}, \epsilon_{12}, D_{1}, f_{1}, k_{1}\right) .
$$

If the fibers are in both $x_{1}$ and $x_{2}$-directions, then we assume as a first approximation that the total specific Helmholtz free energy $\rho \psi_{12}$ is given by a law of mixture of the Helmholtz free energy densities in the $x_{1}$ and in the $x_{2}$-directions

$$
\rho \psi_{12}=(1-f) \rho \psi_{1}+f \rho \psi_{2}
$$

where $f$ is the fraction of fibers in the $x_{2}$-direction $\left(f=f_{2} /\left(f_{1}\right.\right.$ $+f_{2}$ ), and where $f_{1}$ and $f_{2}$ are the volume fraction of fibers in the $x_{1}$ and $x_{2}$-direction, respectively). This assumption also corresponds to a Lin-Taylor Hypothesis. The evolution of the stresses is given by

$$
\begin{gathered}
\sigma_{11}=\rho \frac{\partial \psi_{12}}{\partial \epsilon_{11}}=(1-f) S_{11}+f S_{12} \\
\sigma_{22}=\rho \frac{\partial \psi_{12}}{\partial \epsilon_{22}}=(1-f) S_{21}+f S_{22} \\
\sigma_{12}=\frac{1}{2} \rho \frac{\partial \psi_{12}}{\partial \epsilon_{12}}=2 G_{12} \epsilon_{12}
\end{gathered}
$$

where the explicit expression for $S_{v}$ is given in Appendix A, and the corresponding thermodynamic forces associated to the two independent damage variables $D_{1}$ and $D_{2}$ are

$$
\begin{gathered}
Y_{1}=\rho \frac{\partial \psi_{12}}{\partial D_{1}}=(1-f) \rho \frac{\partial \psi_{1}}{\partial D_{1}} \\
Y_{2}=\rho \frac{\partial \psi_{12}}{\partial D_{2}}=f \rho \frac{\partial \psi_{2}}{\partial D_{2}} .
\end{gathered}
$$

Again, the evolution of the damage variables can either be implicit in terms of the respective normal stresses (model \#1)

$$
\begin{aligned}
& D\left\{^{(1)}=1-\exp \left[-\left\{\frac{\sigma_{11}}{\left(1-\left.D\right|^{(1)}\right) f_{1} \sigma_{c}}\right\}^{m+1}\right]\right. \\
& \quad \text { if } \epsilon_{11}>0 \text { and } \dot{\epsilon}_{11}>0 \\
& D_{2}^{(1)}=1-\exp \left[-\left\{\frac{\sigma_{22}}{\left(1-D_{2}^{(1)}\right) f_{2} \sigma_{c}}\right\}^{n+1}\right] \\
& \text { if } \epsilon_{22}>0 \text { and } \dot{\epsilon}_{22}>0 \text { (18) }
\end{aligned}
$$

or explicit in terms of the respective normal strains (model \#2)

$$
\begin{aligned}
& D_{1}^{(2)}=1-\exp \left[-\left(\frac{\epsilon_{11}}{\epsilon_{c}}\right)^{m+1}\right] \text { if } \epsilon_{11}>0 \text { and } \epsilon_{11}>0 \\
& D_{2}^{(2)}=1-\exp \left[-\left(\frac{\epsilon_{22}}{\epsilon_{c}}\right)^{11+1}\right]
\end{aligned}
$$$$
\text { if } \epsilon_{22}>0 \text { and } k_{22}>0 \text {. }
$$

It is worth noting that we assume that the statistical properties of the fibers are supposed to be identical in both directions. This hypothesis will be maintained throughout the paper since generalization would be straightforward. Both models are studied for shear free states when the strain ratio $\alpha$ (see Eq. (4)), and thus its inverse $\beta$ are given.

3.1 Fallure Criteria for Model \#1. For model \#1, the evolution of the damage variables is implicit in the sense that $D^{(1)}$ (respectively $D_{2}^{(1)}$ ) is a function of the normal stress $\sigma_{11}$ (respectively $\sigma_{22}$ ) and the damage variable $D_{2}^{(1)}$ (respectively $\left.D_{2}^{(1)}\right)$ itself. The evolution is therefore computed by a numerical scheme based upon a Newton method. To study localization and loss of uniqueness, we need to compute the tangent operator, which takes the following form:

$$
\begin{aligned}
& {\left[(1-f) F_{11}+f F_{12}\right]\left(1+f F_{52} F_{72}\right)} \\
& H_{1111}=\frac{-f F_{22} F_{72}\left[(1-f) F_{41}+f F_{42}\right]}{\left[1+f F_{21} F_{72}\right]\left(1+f F_{52} F_{72}\right)} \\
& -f(1-f) F_{22} F_{72} F_{31} F_{71} \\
& H_{2222}=\frac{\left[(1-f) F_{61}+f F_{62}\right]\left[1+(1-f) F_{21} F_{71}\right]}{\left[1+f F_{21} F_{72}\right]\left(1+f F_{52} F_{72}\right)} \\
& -f(1-f) F_{22} F_{72} F_{11} F_{71} \\
& {\left[(1-f) F_{41}+f F_{42}\right]\left(1+f F_{32} F_{72}\right)} \\
& H_{1122}=\frac{-f F_{22} F_{72}\left[(1-f) F_{61}+f F_{62}\right]}{\left[1+f F_{21} F_{72}\right]\left(1+f F_{52} F_{72}\right)} \\
& -f(1-f) F_{22} F_{72} F_{31} F_{71} \\
& \begin{array}{c}
H_{2211}=\frac{\left[(1-f) F_{41}+f F_{42}\right]\left[1+(1-f) F_{21} F_{71}\right]}{\left[1+f F_{21} F_{72}\right]\left(1+f F_{32} F_{72}\right)}-f(1-f) F_{22} F_{72} F_{31} F_{71} \\
H_{1212}=2 G_{12}
\end{array}
\end{aligned}
$$

where the explicit expressions for $F_{i}$ are given in Appendix B.

The loss of uniqueness and localization are investigated when the fiber fraction $f$ and the strain ratio $\alpha$ vary. Although analytical results cannot be derived from criterion (2) in the general case, some simple results can be found when $f$ is equal to 0 or 1. In these cases, the criteria derived by Hild et al. (1992) apply. If $f$ is equal to 0 (fibers only in the $x_{1}$-direction), then localization and loss of uniqueness occur at the same load level when

$$
\begin{gathered}
D_{1}^{(1)}=D_{c}=1-\exp \left(\frac{-1}{m+1}\right) \\
\sigma_{11}=\sigma_{u 1}=f_{1} \sigma_{c}\left(\frac{1}{(m+1) e}\right)^{1 /(m+1)} \\
Y_{1}=Y_{c}=\frac{\sigma_{u 1}^{2}}{2 E_{1}\left(1-D_{c}\right)^{2}}
\end{gathered}
$$

where the stress $\sigma_{u l}$ corresponds to the ultimate tensile strength in the $x_{1}$-direction. It is worth noting that the three previous criteria are easier to compute than the general criterion (2), The direction of localization is $\theta=0 \mathrm{deg}$, i.e., a localization surface perpendicular to the fiber direction.

If $f$ is equal to 1 , the same kind of result apply and the direction of localization is $\theta=90 \mathrm{deg}$, i.e., a localization surface again perpendicular to the fiber direction. When $f \neq 0$ and $f$ $\neq 1$, these results cannot be proved. However the computations show that loss of uniqueness and localization can be described very accurately by the two following criteria: 


$$
\begin{gathered}
\operatorname{Max}\left(\left.D\right|^{(1)}, D_{2}^{(1)}\right)=D_{\mathfrak{i}}=1-\exp \left(\frac{-1}{m+1}\right) \\
\sigma_{11}=\sigma_{111} \text { or } \sigma_{22}=\sigma_{12}
\end{gathered}
$$

when the fiber properties are the same in the two directions. The maximum ertor is .5 percent in terms of criteria (22) and (23)

Criterion (22) shows that for model \#1, maximum damage at localization depends only on the Weibull exponent of the fibers. Furthermore, criterion (23) shows that the maximum normal stress $\sigma_{11}$ (respectively $\sigma_{23}$ ) depends only on the volume fraction of fibers in the $x_{1}$ (respectively $x_{2^{-}}$) direction and on the fiber characteristics. This result is consistent with some experimental observations on woven carbon matrix composites reinforced with $\mathrm{SiC}$ (Nicalon) fibers (Heredia et al., 1992). On the other hand, the localization angle is dependent on the fiber percentage $f$ (see Fig. 2). When the fiber percentage $f$ and the sign of the stratus $\epsilon_{11}$ and $\varepsilon_{22}$ are constant, the variation of the localization angle is due to the fact that the maximum tensile stress is either reached in the $x_{1}$ or in the $x_{2}$-direction.

Moreover, if the strain ratio $\alpha$ is different from 0 and 1 then there is a complete symmelry of the results. If the strain ratio $\alpha$ is positive, the strains $\epsilon_{11}$ and $\epsilon_{22}$ are positive, changing $\alpha$ into $\beta, f_{2}$ into $f_{1}$, changes $f$ into $1-f_{1}$ and alters the absolute value of the localization angle $|\theta|$ into $\pi / 2-|\theta|$ and keeps the naximum stresses and damage levels constant. These two properties arc referred to as symmetry properties, and are mainly due to the features of Eqs. (4), (8), (14), and (15).

When the strain ratio $\alpha$ is equal to 1 and the fiber percentage $f$ is equal to .5, the localization angle is undetermined. This is due to the vanishing of the three constants $a, b$, and $c$ in Eq. (6), for $H_{1111}=H_{1122}=H_{2211}=H_{2222}=0$. Any value of the angle $\theta$ satisfies Eq. (6). This phenomenon can be observed when the fiber percentage $f$ is different from L: if $\sigma_{11}=\sigma_{11}$ and $\sigma_{22}=\sigma_{u 2}$ simultaneously, then $D^{(1)}=D_{2}^{(1)}=D_{c}$, and $H_{1111}$ $=H_{1122}=H_{2211}=H_{2222}=0$. This particular result shows that in terms of this model, for a given strain ratio $\alpha$, it is possible to optimize locally a CMC reinforced by fibers in two perpendicular directions. Indeed, in terms of fiber breakage, a condition $\sigma_{11}=\sigma_{u 1}$ and $\sigma_{22}=\sigma_{12}$ leads to an optimum of the fiber behavior in both directions.

Model \#I constitutes a straightfortward generalization of the fiber bundle models studied by Krajcinovic and Silva (1982), and Hult and Travnicek (1983). Finally, a shear stress has no influence on all the previous results since wc assumed no coupling between the damage variables and the shear strain or stress for both model \#1 and \#2.

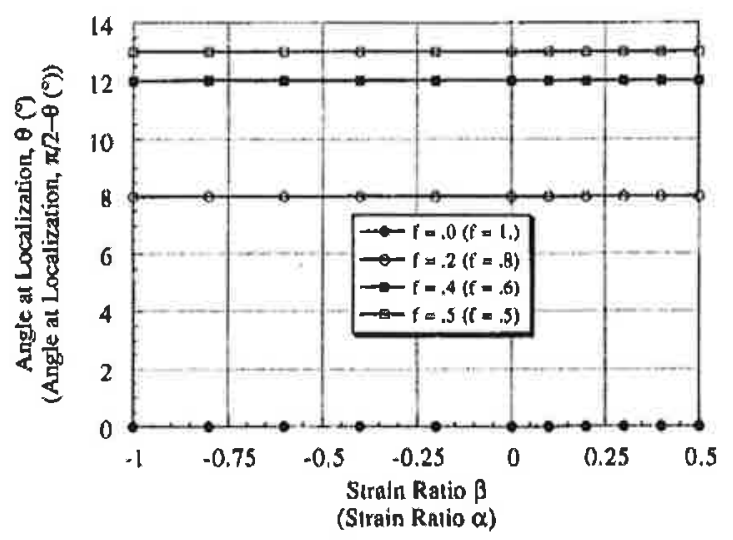

Fig. 2 Absalute value of the localization angle In degrees at locallzation for model $\$ 1$, the maln caption of the axes corresponds to the case where $f_{2}=.5, f_{1}=.0, .125, .333, .6$, and the captions in brackets correspond to the cases where $f_{1}=.5, f_{2}=0, .125, .333, .5$

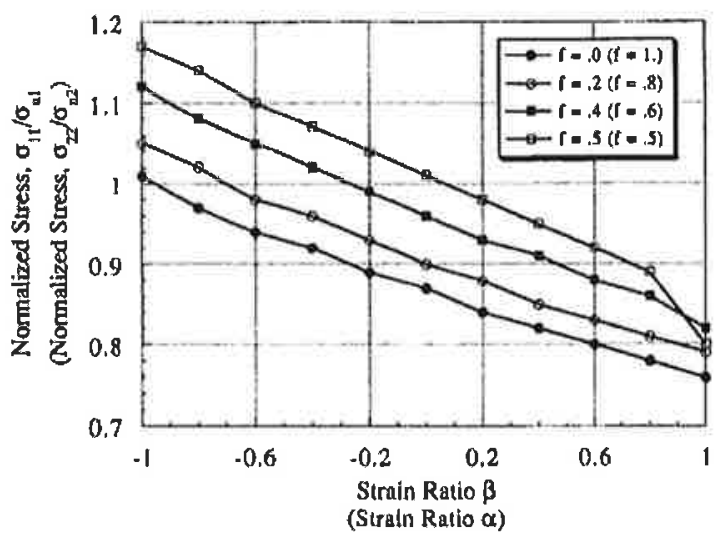

Fig. 3 Normalized maximum stress at localizatlon for model $\# 2$, the main oaptlon of the axes corresponds to the case where $f_{2}=.5, f_{1}=.0$, $.125, .333, .5$, and the captions in brackets correspond to the cases where $f_{1}=.5, t_{2}=.0, .125, .333, .5$

3.2 Study of Localization With Model \#2. For model \#2, the evolution of the damage variables is explicit and thereforc is easier to compute. The tangent operator takes the form

$$
\begin{gathered}
H_{1111}=(1-f)\left(F_{11}-F_{21} F_{31}\right)+f F_{12} \\
H_{2222}=(1-f) F_{62}+f\left(F_{42}-F_{52} F_{32}\right) \\
H_{1122}=(1-f) F_{41}+f\left(F_{42}-F_{22} F_{32}\right) \\
H_{2211}=(1-f)\left(F_{11}-F_{21} F_{31}\right)+f F_{42} \\
H_{1212}=2 G_{12}
\end{gathered}
$$

where the explicit expressions for $F_{\text {, }}$ are given in Appendix B. As shown in the case of fibers in only one direction (Hild at al., 1992), the localization criterion cannot be described by some simple criteria as those given by model \#1. When fibers are in both directions the latter results are confirmed. A first consequence is that an optimization procedure can be performed since the maximum stress at localization, and the maximum damage at localization are dependent on both the strain ratio $\alpha$ and on the fiber percentage $f$.

Since the elastic law given in Eqs. (16) is identical for both models, the symmetry properties apply also for model \#2 (see Figs. 3, 4, and 5). It can also be noticed that the maximum stress at localization varies with the fiber fraction $f$ and with the strain ratio $\alpha$.

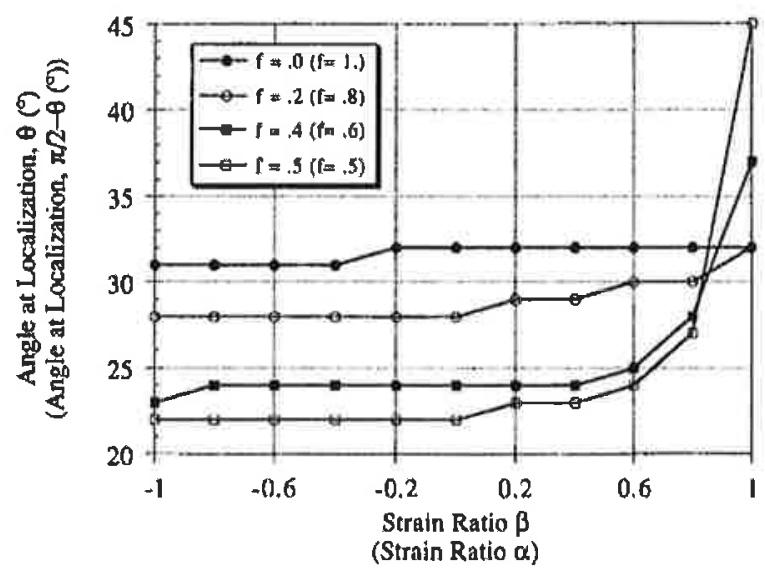

Fig. 4 Absolute value of the localization angle in degrees for model \#2, the main caption of the exes corresponds to the case where $t_{2}=.5, f_{1}$ $=.0, .125, .933, .5$, and the captlons in breckets correspond to the cases where $f_{1}=.5, f_{2}=.0, .125, .333, .5$ 


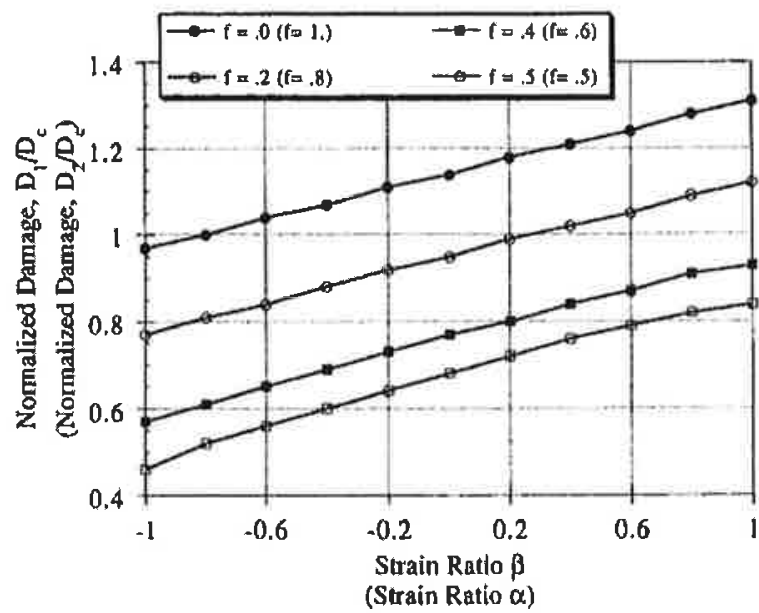

Fig. 5 Maximum normalized damage value at locallzation $(m=4$.) for model $\$ 2$, the mein caption of the axes corresponds to the case where $f_{2}=.5, f_{1}=.0, .125, .333, .5$, and the captlons in brackets correspond to the cases where $f_{1}=.5, f_{2}=.0, .125, .333, .5$

In the experiments reported by Heredia et al. (1992) the stress at localization was given by the ultimate tensile strength corresponding to the volume fraction of fibers in the same direction. This is not found by using model $\# 2$. Indeed, in a tensile test, when $f_{1}=f_{2}=.5$ the maximum stress $\sigma_{22}$ normalized by the ultimate tensile strength $\sigma_{12}$ is given by, 63 , whereas the same tensile test when $f_{1}=.0$ and $f_{2}=.5$ would give a normalized tensile strength $\sigma_{22} / \sigma_{t 2}$ equal to 1 . On the other hand, the damage at localization $D_{2}$ normalized by the critical damage $D_{c}$. is equal to 1.04 when $f_{1}=.5$ and $f_{2}=.5$ and is equal to 1 . when $f_{1}=.0$ and $f_{2}=.5$.

It is too early to draw a final conclusion, but it seems that the predictions of model \#1 correspond more to reality than those of model \#2. On the other hand, model \#2 turned out to give results very close to model \# I when applied to structures with fibers in one direction (Hild et al., 1992). This will be addressed in the case of structures with fibers in two perpendicular directions such as spinning disks.

\section{Conclusions}

Using a one-dimensional study of fiber breakage modeled by a single damage variable, two models are derived. Both of them are then generalized to a two-dimensional plane stress analysis, with fibers in two perpendicular directions. Whereas model \#1 constitutes a straightforward generalization of the elementary study, model \#2 exhibits different features. Indeed, loss of uniqueness and localization can be described by some very simple criteria referring to Continuum Damage Mechanics for model \#1. Conversely, these simple criteria do not apply for model \#2. Physically, model \#1 gives a better description of some experimental trends observed in the case of a carbon matrix reinforced with silicon carbide (Nicalon) fibers in two perpendicular directions. On the other hand, model \#2 is casicr to compute, and when applied to the study of spinning disc with fibers in one direction, it leads to load leveis at localization of the same order of magnitude as model \#1 (Hild et al., 1992).

Lastly, this study shows that the localization for model \#1 can be described by using criterion (23) derived from the general criterion of localization (2). This criterion can also be used for a computation in elasticity and may turn out to be sufficient in first approximation to predict load levels at which a macrocrack initiates, instead of using a computation in elasticity coupled with damage.

\section{Acknowledgments}

The authors gratefully acknowledge the linancial support of the U.S. Air Force through contract AFOSR-90-0132 with the
Department of Mechanical and Environmental Engineering, University of California at Santa Barbara, and the DARPA University Research Initiative with the University of California at Santa Barbara (ONR contract N00014-86-K0753).

\section{References}

Benallal, A., Billatdon, R., and Geymonul, G., 199 la, "Localizalinn Phenomenta ut the Boundaries and Interfaces of Solicls," Ird Conference on Constitutive Laws for Engineering Maserials: Theory and Applications, C. S. Desai and G. Franlyiskonix, eds., Tucson, AZ, Jalu.

Bentallal, A., Billardon, R., and Lemaitre, J, 199/b, "Continuum Damage Mechanics and Local Approach to Fracture: Numerical Procedures," Comp. Meth. in Appl. Merch and Eitg., Vol, $92, \mathrm{pp} .141-155$.

Billurdon, R., and Doghri, J., 1989a, "Prévision de l"amorçage d'une maerofissure par la Inealisation de l'etdonmagement." $C$. R. Acad. Sci. Paris. Vol 308, Seric II, pp. 347-352

Billardon, R., aud Doghri, L., 1989b, "Localization Bifurcation Annlysis for Damage Softening Elasto-Plastic Materials," Strain Localizarion and Size Effect dive to Crarking and Damage, J. Maxars and Z. P. Hazant eds., Elsevici, New York, pp. 295-307.

Borré, $G_{1}$ and Maicr, $G_{4}, 1989$, , On Lineur versus Nontincar Flaw Rules in Strain Localizntion Analysis," Mectanica, Vol. 24, 36-41,

Colemnn, B. D., 1958, "On ithe Strength of Classicnl Fibers and Fiber Bundles," J. Mect. Phys. Solids, Vol, 7, pp. 60-70.

Curtin, W. A., 1991, "Theory of Mechanicnl Properties of Ceramic-Matrix Composiles," J. Am. Ceram. Sor., Vol, 74, No. 11, pp. $2837-2845$.

Doghri, l., 1989, "Etude de la localisation de l'endommagement." These de I'Universitế Paris 6, May.

Hadamard, J. 1903, leçon sur la propagation des ondes et les équations de l'hydrodynamigue, Librniries sticntifiques $\mathrm{A}$, Hermann, Paris.

Heredia, F. E., Spearing, S. M. Evans, A. G., Mosher, P., and Curtin, W. A. 1992. "Mechanical Properties of Carbon Matrix Composites Reiuforeed with

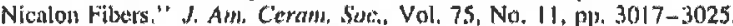

Henstenburg, R. B., and Phoenix, S, L, 1989, "Interfacial Shcar Strength Studies Using the Single-Filament-Composite Test. Part II: A Probability Model and Monte-Carlo Simulations," Pplym. Comp. Vol. 10, No, 5, pp. 389-406.

Hild, F., Larsson, P, L., und Leckie. F. A., 1992, "Lncalization Due to Damage in Frber Reintoreed Composites, "Int. J. Solids Strircs., Vol. 29. No. 4, pp. 32213238 .

Hild, F., Domergue, J.-M., Evans, A. G., and Leckic, F. A, 1994, "Tensile und Flexural Ultimate Strength of Fiber Reinforeed Ceramic-Malrix Comprosites," Int. J. Solids Sirict., Vol, 31, No. 7, pp. 1035-1045.

Hill, R., 1962, "Accelerntion Waves in Sollds," J. Mech. Phys, Sollids, Vol. 10, pp. $1-16$

Hult, J., and Travnicek, L., 1983, "Carrying Cupacity of Fiber Bundles with Varying Strength and Stiffness," Journal de Mecomique Theorique es Appliquêe, Val, 2, No, 2, np. 643-657

Krajcinovic, D., and Silva, M. A. G., 1982, "Stutistienl Aspects of the Comtinuous Damago Theory," Inl. J. Solids Struct, Vol. 18, No. 7, pp. 551-562.

Mandel, J., 1962, "Ondes Plastiques dans un Milieu Indéfini à Trois Dimensions," J. de Mécanique Vol. I, No. I, pp. 3-30.

Orliz, M., Leroy, Y., and Needelman, A. 1987, "A Finite Element Method for l.ocalized Failure Analysis," Comput. Meths. Appl. Eng., Vol. 61, pp. 189214.

Rice, J. R, 1976, "The Localization of Plastic Deformations," Theoreticat and Applied Mechanicr, W. T. Koiter, ed., Elsevier, New York, pp, 207-220.

Rice, J. R, and Rudnicki, J. W, 1980, "A Note on Some Fontures of the theory of' localization of Deformation," Im. J. Solids' Struct., Vol. 16, pp. 597605.

Rudnicki, J. W., and Rice, J, R, 1975, "Conditions for Localization of Deformation in Pressure-Sansitive Dilatant Materials," J. Mech. Phys. Sollds, Vol. 23, pp. $371-394$.

Weibull, W., 19.39, "A Statistical Theory of the Strength of Materials." Ingentirsvetenskapakrdemien.s. Hundlingar $\mathrm{Nr}$ isi.

\section{Appendix A}

$$
\begin{gathered}
k_{1}=\frac{E_{2}\left(f_{1}\right)}{E_{1}} \\
k_{2}=\frac{E_{2}\left(f_{2}\right)}{E_{1}} \\
S_{11}=\frac{E_{2}\left(f_{1}\right)\left(1-D_{1}\right)}{1-\nu_{12}^{2}\left(1-D_{1}\right) k_{1}}\left(\epsilon_{11}+\nu_{12} \epsilon_{22}\right) \\
S_{12}=\frac{E_{2}\left(f_{2}\right)}{k_{2}\left[1-\nu_{12}^{2}\left(1-D_{2}\right) k_{2}\right]}\left[\epsilon_{11}+\nu_{12}\left(1-D_{2}\right) k_{2} E_{22}\right] \\
S_{21}=\frac{E_{2}\left(f_{1}\right)}{k_{1}\left[1-\nu_{12}^{2}\left(1-D_{1}\right) k_{1}\right]}\left[\epsilon_{22}+\nu_{12}\left(1-D_{1}\right) k_{1} \epsilon_{11}\right]
\end{gathered}
$$




$$
\begin{gathered}
S_{22}=\frac{E_{2}\left(f_{2}\right)\left(1-D_{2}\right)}{1-\nu_{12}^{2}\left(1-D_{2}\right) k_{2}}\left(\epsilon_{22}+\nu_{12} \epsilon_{11}\right) \\
\text { A p pendi x B B } \\
F_{11}=\frac{E_{2}\left(f_{1}\right)\left(1-D_{1}\right)}{1-\nu_{12}^{2}\left(1-D_{1}\right) k_{1}} \\
F_{12}=\frac{E_{2}\left(f_{2}\right)}{k_{2}\left(1-\nu_{12}^{2}\left(1-D_{2}\right) k_{2}\right)} \\
F_{21}=\frac{E_{2}\left(f_{1}\right)\left(\nu_{12} \epsilon_{11}+\epsilon_{22}\right)}{\left(1-\nu_{12}^{2}\left(1-D_{1}\right) k_{1}\right)^{2}} \\
F_{22}=\frac{E_{2}\left(f_{2}\right) \nu_{12}\left(\nu_{12} \epsilon_{11}+\epsilon_{22}\right)}{\left(1-\nu_{12}^{2}\left(1-D_{2}\right) k_{2}\right)^{2}} \\
F_{41}=\frac{E_{2}\left(f_{1}\right) \nu_{12}\left(1-D_{1}\right)}{1-\nu_{12}^{2}\left(1-D_{1}\right) k_{1}} \\
F_{42}=\frac{E_{2}\left(f_{2}\right) \nu_{12}\left(1-D_{2}\right)}{1-\nu_{12}^{2}\left(1-D_{2}\right) k_{2}} \\
F_{51}=\frac{E_{2}\left(f_{1}\right) \nu_{12}\left(\nu_{12} \epsilon_{11}+\epsilon_{22}\right)}{\left(1-\nu_{12}^{2}\left(1-D_{1}\right) k_{1}\right)^{2}} \\
F_{52}=\frac{E_{2}\left(f_{2}\right)\left(\nu_{12} \epsilon_{11}+\epsilon_{22}\right)}{\left(1-\nu_{12}^{2}\left(1-D_{2}\right) k_{2}\right)^{2}}
\end{gathered}
$$

$$
\begin{gathered}
F_{61}=\frac{E_{2}\left(f_{1}\right)}{k_{1}\left(1-\nu_{12}^{2}\left(1-D_{1}\right) k_{1}\right)} \\
F_{62}=\frac{E_{2}\left(f_{2}\right)\left(1-D_{2}\right)}{1-\nu_{12}^{2}\left(1-D_{2}\right) k_{2}} \\
\left.F_{31}=\frac{m+1}{\epsilon_{c}}\left(\frac{\epsilon_{11}}{\epsilon_{c}}\right)^{m} \exp \left[-\frac{\epsilon_{11}}{\epsilon_{r}}\right)^{m+1}\right] \\
F_{32}=\frac{m+1}{\epsilon_{c}}\left(\frac{\epsilon_{22}}{\epsilon_{c}}\right)^{m} \exp \left[-\left(\frac{\epsilon_{22}}{\epsilon_{c}}\right)^{m+1}\right] \\
F_{71}=\frac{\frac{m+1}{f_{1} \sigma_{c}}\left[\frac{\sigma_{11}}{1-(m+1)\left[\frac{\sigma_{11}}{\left(1-D_{1}\right) f_{1} \sigma_{r}}\right]^{m+1}}\right]^{m+1}}{\frac{m+1}{f_{2} \sigma_{c}}\left[\frac{\sigma_{22}}{\left(1-D_{2}\right) f_{2} \sigma_{c}}\right]^{m}} \\
F_{72}=\frac{\sigma_{22}}{1-(m+1)\left[\frac{\left.D_{2}\right) f_{2} \sigma_{c}}{\left(1-D_{c}\right.}\right]^{m+1}}
\end{gathered}
$$

